\title{
Investigation of mechanical characteristics of GFRP composites produced from chopped glass fiber and application of taguchi methods to turning operations
}

\author{
Yahya Hışman Çelik ${ }^{1}$ D . Cihat Türkan ${ }^{1}$
}

Received: 3 January 2020 / Accepted: 2 April 2020 / Published online: 8 April 2020

(c) Springer Nature Switzerland AG 2020

\begin{abstract}
Glass fiber-reinforced plastic (GFRP) composites take place in engineering materials owing to their low-weight and high-mechanical properties. In some cases, they need to be shaped by machining before using in industrial applications. However, when these composites are machined, many problems such as bad surface quality, rapid tool wear are encountered. Therefore, optimization of cutting parameters is essential to eliminate or minimize these problems. In this study, GFRP composites were produced by combining polyester matrix material with glass fibers (GF) having $6 \mathrm{~mm}$, 6-12 mm, $12 \mathrm{~mm}$ fiber length, and 20\%,25\%,30\% fiber ratio by weight. The tensile strengths of these composites were investigated. Turning tests were also performed with cutting speeds of 40,80 , and $120 \mathrm{~m} / \mathrm{min}$, feed rates of $0.1,0.2$ and $0.3 \mathrm{~mm} / \mathrm{rev}$, and depth of cut of 1,2 , and $3 \mathrm{~mm}$, according to Taguchi $L_{27}$ standard orthogonal array method. The effect of fiber length and ratio, and cutting parameters on cutting forces and surface roughness were analyzed. As a result of the experiments, it was observed that the reinforced polymer matrix with GF provide to increase the tensile strength. The highest tensile strength was obtained as $55.95 \mathrm{MPa}$ from the composite having a fiber length of $12 \mathrm{~mm}$ and a fiber ratio of $25 \%$. Besides, the feed rate was determined as the most effective parameter among the all parameters on both cutting force and surface roughness. Therefore, the feed rate should be chosen low for lower cutting force and surface roughness values.
\end{abstract}

Keywords Cutting force · GFRP composite · Taguchi $\cdot$ Tensile strength · Turning · Surface roughness

\section{Introduction}

GFRP composites are one of the most commonly used engineering materials in application areas such as aerospace, defense, construction, automotive, marine, nuclear, robot, healthcare, and chemical industries due to their easy availability, low cost, high hardness, high fracture strength [1-3]. They meet the special features of the developing technology better than traditional materials. However, their fabrication methods and fiber types influence the mechanical and tribological properties. Sivasankaran et al. [4] fabricated GFRP composites from glass fiber mat and glass fiber woven fabrics by filament winding. The mechanical properties of GFRP composites produced with woven fabrics were found to be higher than those produced with glass fiber mat. Jawali et al. [5] fabricated short GF-reinforced nylon six composites having different weight ratios by the melting-mixing method. It was observed that wear resistance of composites increased with GF content. As the mechanical and tribological behaviors of GFRP composites are improved, their usage areas are increasing day by day and they are subjected to different processing methods [6-9].

Yahya Hışman Çelik, yahyahisman.celik@batman.edu.tr| ${ }^{1}$ Department of Mechanical Engineering, Faculty of Engineering-Architecture, Batman University, Batman, Turkey. 
Although GFRP composites are shaped by different production methods, their dimensions and geometric shapes must be taken into account. In some cases, machining methods such as turning, milling, drilling are often needed to give the final shape of these composites. As GFRP composites have the anisotropic structure, problems such as rapid tool wear, bad surface quality, excessive cutting force and power consumption are encountered during machining [10-12]. These problems can be controlled with cutting parameters such as cutting tool material, feed rate, cutting speed, and depth of cut [13-15]. Sarma et al. [16] investigated the effects of feed rate, cutting speed, depth of cut, and fiber orientation angle on cutting forces. Cutting forces was determined to increase with increasing the feed rate, cutting speed, depth of cut, and fiber orientation angle. However, the cutting forces started to decrease depending on increasing cutting speed when the cutting speed was above a critical value. Işık and Kentli [17] examined the effects of cutting parameters on cutting force and the material removal rate in machining of GFRP composites at different process parameters. The results showed that optimum cutting parameters varied with the insert radius. Gill et al. [18] researched the effects of tool geometry, feed rate, cutting speed, and depth of cut on cutting forces such as tangential, radial, and feed forces in turning with carbide tools having a different radius and chip angles of GFRP composites. The tool geometry and depth of cut were expressed to have significant effects on cutting forces. Paula Davim and Mata [19] investigated the effects of cutting parameters on machinability with PCD and K15 cutting tools in the machining of GFRP composites fabricated by hand lay-up method. The specific cutting pressure decreased with increasing feed rate and cutting speed. They also observed that the PCD cutting tool performed better machinability performance than the K15 cutting tool. In another study, Davim and Mata [20] turned GFRP composites in different cutting parameters. The feed rate was found as the most effective machining parameter on surface roughness and specific cutting pressure due to the physical and statistical effect. GFRP composites fabricated by hand lay-up method provided a better processability index than those produced by the filament winding method. Hussain et al. [21] investigated the effects of fiber orientation angle, cutting tool type (K20, CBN, and $P(D)$, feed rate, cutting speed, and depth of cut on power consumption in turning of GFRP composite pipes. In experimental results, they stated that power consumption was lower in low feed rate, cutting speed and fiber orientation angle, and medium depth of cut. They also impressed that the PCD tool performed the best in power consumption. Işık [22] examined the effects of cutting parameters such as depth of cut, feed rate, cutting speed, and tool geometry on surface roughness in machining of
GFRP composites. The cutting force and power consumption could be controlled with cutting parameters and tool materials [23-25]. Surface roughness also varies depending on cutting parameters and tool material. It was recommended that the GFRP composites should be turned at high cutting speed, low feed rate, and high depth of cut [26]. However, Kumar Parida et al. [27] stated that optimum cutting parameters for better surface quality were obtained from low feed rate, cutting speed, and depth of cut, and they stated that the most effective parameter was cutting speed. In a study conducted by Hussain et al. [28], surface roughness value increased with increasing fiber orientation angle and feed rate, and it decreased with increasing cutting speed and depth of cut. According to Gupta and Kumar [29], in turning of GFRP composites, surface roughness value decreased with increasing tool nose radius. Surface roughness value was seen to increase with increasing feed rate, cutting speed and depth of cut in their experimental results. In some studies [30, 31], it was emphasized that an increase the feed rate generally had a negative effect on surface roughness. However, this situation showed different behavior for cutting speeds and depth of cut.

When the studies are investigated, it has been seen that the effects of fiber orientation angle, composite production method, tool material, cutting parameters such as tool geometry, feed rate, cutting speed, and depth of cut on surface roughness, cutting force, power consumption, and tool wear were investigated. The optimization of cutting parameters was also made. However, it was observed that there isn't the detailed study about the production and turning of GFRP composites produced using chopped fibers of different fiber lengths and different ratios. In this study, GFRP composites having different fiber lengths and ratios were produced. The tensile strength of these composites was determined. Furthermore, these composites were turned in different cutting parameters according to the Taguchi $\mathrm{L}_{27}$ standard orthogonal array method. The effects of cutting parameters, fiber length, fiber ratio and tensile strength on cutting force and surface roughness were researched.

\section{Materials, methodology and experimental procedure}

\subsection{Production and tensile test of GFRP composites}

Chopped glass fibers (GFs) with different fiber lengths as reinforcement elements and Poliber brand cast polyester as the matrix material were commercially provided for the production of GFRP composites. Fiber lengths of GFs were $6 \mathrm{~mm}$ and $12 \mathrm{~mm}$. Some properties of GF reinforcement 
Table 1 Properties of GF reinforcement

\begin{tabular}{lll}
\hline Properties & Values & Units \\
\hline Tensile strength & 3400 & $\mathrm{MPa}$ \\
Elasticity modulus & 77 & $\mathrm{GPa}$ \\
Application temperature limits & $-60 \ldots+650$ & ${ }^{\circ} \mathrm{C}$ \\
Melting temperature & 1120 & ${ }^{\circ} \mathrm{C}$ \\
Specific weight & 2.60 & $\mathrm{~g} / \mathrm{cm}^{3}$ \\
Diameter of fiber & $13-15$ & $\mu \mathrm{m}$ \\
\hline
\end{tabular}

Table 2 Lengths and ratios of GF reinforcement

\begin{tabular}{lll}
\hline Fiber & Values & Units \\
\hline Length & $6,6-12$ and 12 & $\mathrm{~mm}$ \\
Ratio & 20, 25 and 30 & $\% \mathrm{wt}$ \\
\hline
\end{tabular}

elements are given in Table 1. Fiber lengths and ratios are also given in Table 2 .

Chopped fibers were kept in the oven at $100^{\circ} \mathrm{C}$ temperature for $2 \mathrm{~h}$ and removed the moisture in the fibers. The reinforcement and matrix materials were weighted with the Precisa brand XB 220A precision scale with a capacity of $220 \mathrm{~g}$ and a sensitivity of $0.1 \mathrm{mg}$. Then, mixtures were prepared in the determined proportions according to the combination of parameters given in Table 2 . The production steps of the reinforced mixture having fiber length of $12 \mathrm{~mm}$ and fiber ratio of $30 \%$ weight are given in Fig. 1.

The mixture was poured into the prepared silicone mold to determine the tensile strength given in Fig. 2, and the remaining mixture was poured into a cylindrical plastic mold having an internal diameter of $44 \mathrm{~mm}$ for turning tests.

The molded mixtures were cured for $24 \mathrm{~h}$. Then, the composites were took out from the molds. Composites were kept at room temperature for 14 days to provide complete curing. The images of the GFRP composites produced for turning tests are given in Fig. 3 .

Tensile tests were performed with Shimadzu brand universal tensile tester shown in Fig. 4 in a speed of $1 \mathrm{~mm} /$ $\mathrm{min}$. The data obtained from the tensile tester were used for stress-strain graphs of the samples.

\subsection{Turning tests and Taguchi test design}

In turning of GFRP composites, a number of tests are required to determine the effects of fiber length, fiber ratio, feed rate, cutting speed, and depth of cut on cutting force and surface roughness values. For turning experiments, tungsten carbide cutting tool coated TiAIN triangular YBG205 class was used; and cutting parameters given in Table 3 were selected. These parameters were determined according to the recommended cutting parameters for cutting tools and the literature studies [15, 19-21, 23].

When turning tests are performed depending on the fiber length and ratio, and cutting parameters, 243 tests are required totally. Turning experiments were performed by designing the experimental setup according to Taguchi $L_{27}$, 3-level standard orthogonal array to reduce the number of tests, and to determine the effect factor of the determined parameters on cutting force and surface roughness. 27 turning tests were carried out according to
Fig. 1 Production stages of the reinforcement and matrix material mixtures

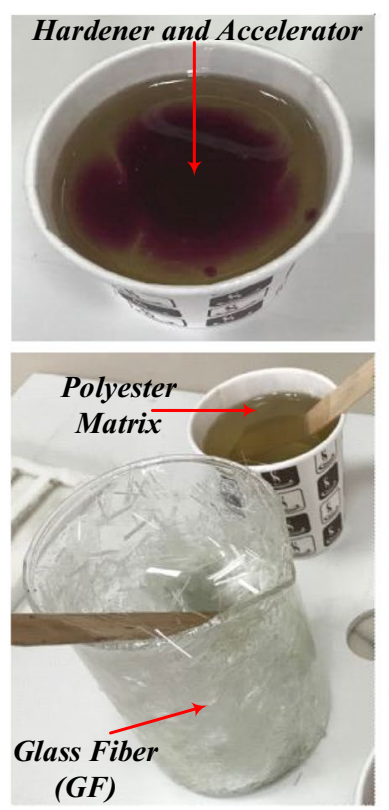

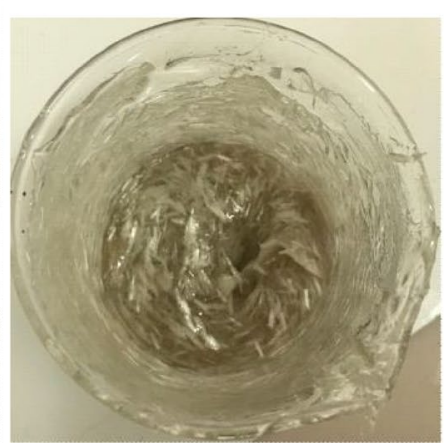

Mixture of reinforcement and matrix

Polyester + Hardener + Accelerator 


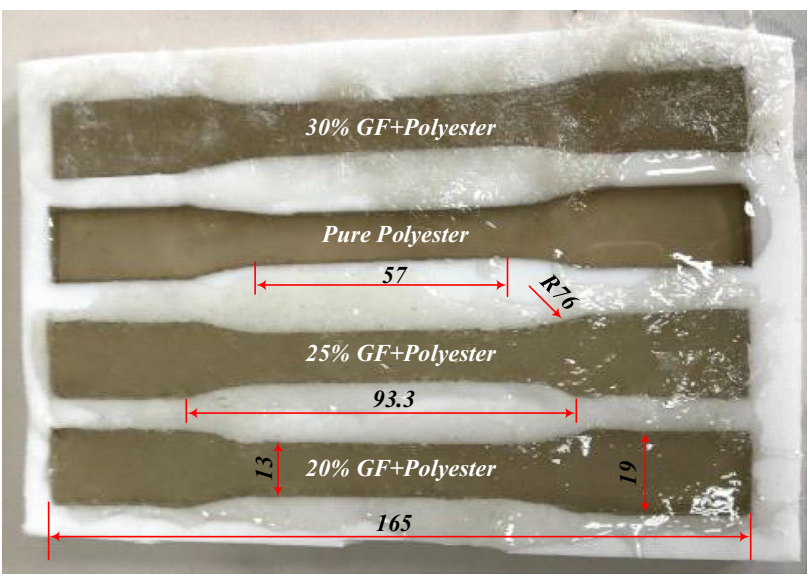

Fig. 2 Dimensions of the tensile test specimens and pouring the mixtures into the silicone mold

Table 3 Cutting parameters

\begin{tabular}{llll}
\hline Parameters & Units & Symbols & Values \\
\hline Cutting speed & $\mathrm{m} / \mathrm{min}$ & $V$ & 40,80 and 120 \\
Feed rate & $\mathrm{mm} / \mathrm{rev}$ & $f$ & $0.1,0.2$ and 0.3 \\
Depth of cut & $\mathrm{mm}$ & $a$ & 1,2 and 3 \\
Cutting length & $\mathrm{mm}$ & $I$ & 20 \\
\hline
\end{tabular}

Table 4 Parameters and levels

\begin{tabular}{lllll}
\hline Variables & Units & \multicolumn{2}{l}{ Levels } & \\
\cline { 3 - 5 } & & 1 & 2 & 3 \\
\hline Fiber length & $\mathrm{mm}$ & 6 & $6-12$ & 12 \\
Fiber ratio & $\% \mathrm{wt}$ & 20 & 25 & 30 \\
Cutting speed & $\mathrm{m} / \mathrm{min}$ & 40 & 80 & 120 \\
Feed rate & $\mathrm{mm} / \mathrm{rev}$ & 0.1 & 0.2 & 0.3 \\
Depth of cut & $\mathrm{mm}$ & 1 & 2 & 3 \\
\hline
\end{tabular}

Fig. 3 GFRP reinforced composite materials

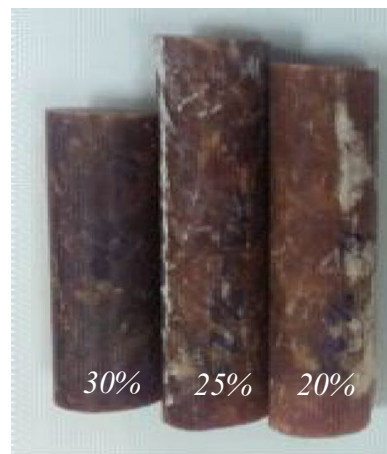

Fiber length: $6 \mathrm{~mm}$

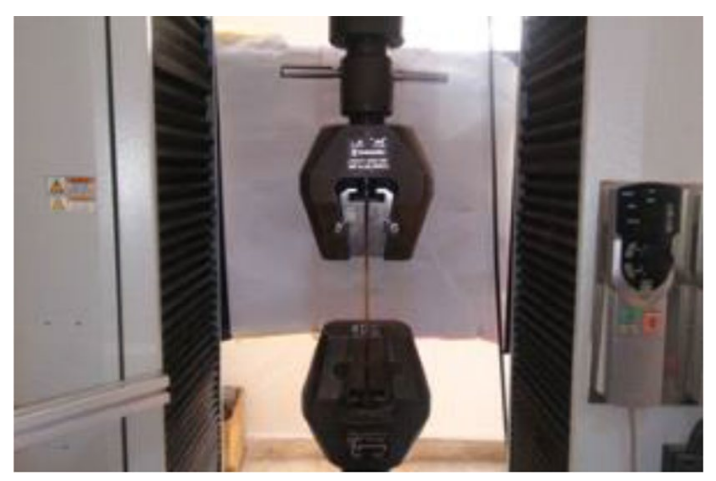

Fig. 4 Shimadzu brand tensile tester

this test design. The parameters and levels for Taguchi $L_{27}$ standard orthogonal array are given in Table 4.

Turning experiments were carried out SMARC brand CAK6166B X 2000 CNC lathe. The counter diameter of the machine and the distance between the tailstock were $660 \mathrm{~mm}$ and $2000 \mathrm{~mm}$ respectively and the spindle speed was in the range of 21-1620 rpm. The main motor power was $11 \mathrm{~kW}$, and it was turret type 4 and vertical, and the diameter of the tailstock was $75 \mathrm{~mm}$, and the tool size was $25 \times 25 \mathrm{~mm}$.

\subsection{Determination of cutting force and surface roughness}

Kistler 9257B type dynamometer was connected to $\mathrm{CNC}$ lathe to measure cutting forces. Signals from the dynamometer were transferred to the Kistler 5070A amplifier. Force signals from the dynamometer were transferred to the computer with DynoWare software and plotted. The experimental setup is shown in Fig. 5. 

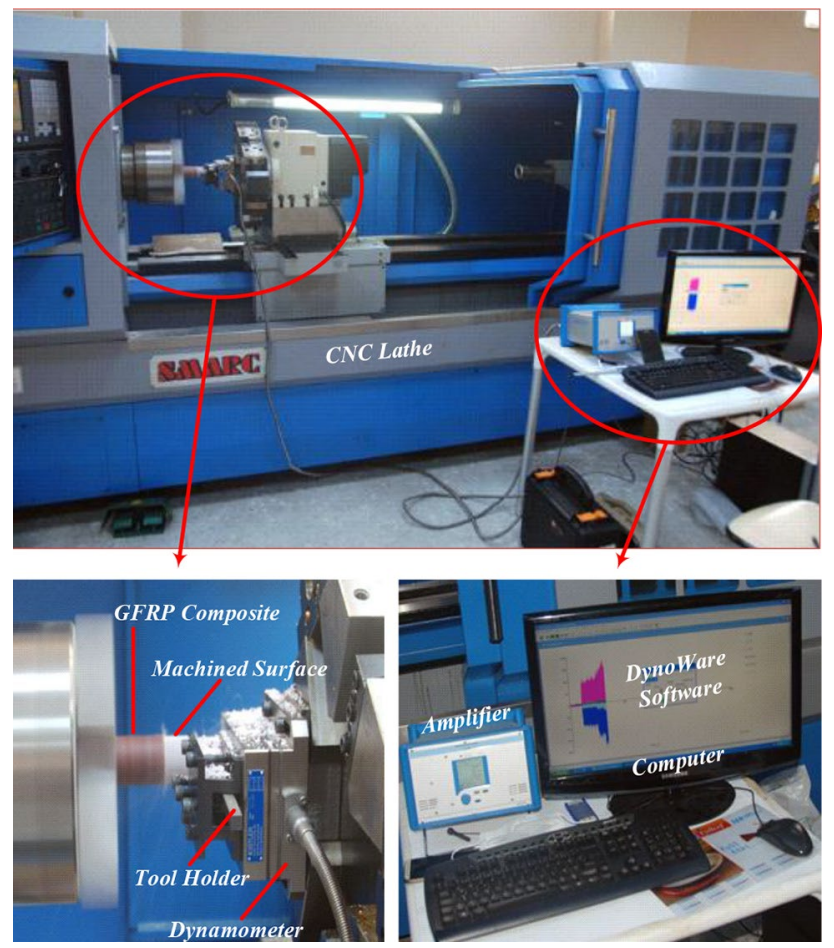

Fig. 5 The experimental setup and the measurement of cutting forces

DynoWare software calculates minimum, maximum, and average values for $F_{x}, F_{y}$ and $F_{z}$ forces. Values to be considered among these values are the average forces. While the force in the direction of feed is only of great importance in drilling, all forces in the directions of feed, rotation, and radial are of great importance in the turning. In this direction, the cutting force must be considered in turning tests. The cutting force $(F)$ is calculated in Eq. 1 by writing the average forces in the $F_{x^{\prime}} F_{y}$, and $F_{z}$ directions:

$F=\sqrt{F_{x}^{2}+F_{y}^{2}+F_{z}^{2}}$

The roughness values of the machined surfaces of GFRP composites were measured with Time TR-110 portable surface roughness tester. This surface roughness tester was a digital display and pocket type and could be used for measuring flat and cylindrical workpieces. In the surface roughness measurement, the cut-off length was chosen as $0.8 \mathrm{~mm}$. The surface roughness values were measured from four different regions over the machined surface, and their average values were calculated. Thus, average surface roughness values $(\mathrm{Ra})$ were determined.

\section{Experimental results and discussions}

\subsection{Tensile strength results}

Tensile tests were carried out to determine the tensile strength of GFRP composites having different fiber lengths and ratios. Tensile specimens were produced by ASTM D638 Type I of the ASTM Standard, and the tests were performed at a speed of $1 \mathrm{~mm} / \mathrm{min}$. Stress-strain graphs obtained from the result of the test are given in Fig. 6 .

Since the mechanical properties of polyester matrix materials depend on the bond between the molecules at each point, their tensile and compressive strengths are related to the bond's strength. However, the addition of reinforcing materials increases or decreases the strength of the matrix material according to the reinforcement type and properties. In tensile tests, the tensile strength of pure polyester was obtained as $24.6 \mathrm{MPa}$. For fiber length $6 \mathrm{~mm}$, the tensile strengths of the composites having fiber ratios of $20 \%, 25 \%$, and $30 \%$ were $36.17 \mathrm{MPa}, 53.85 \mathrm{MPa}$, and $42.05 \mathrm{MPa}$, respectively. For fiber length 6-12 mm, the tensile strengths of the composites having fiber ratios of $20 \%$, $25 \%$, and $30 \%$ were $37.85 \mathrm{MPa}$, $48.6 \mathrm{MPa}$, and $47.98 \mathrm{MPa}$, respectively. For fiber length $12 \mathrm{~mm}$, the tensile strengths of the composites having fiber ratios of $20 \%, 25 \%$, and $30 \%$ were $43.3 \mathrm{MPa}$, $55.95 \mathrm{MPa}$, and $51.18 \mathrm{MPa}$, respectively. It was observed that tensile strengths increased in all fiber lengths with increasing fiber ratio. When tensile test results were examined, it was seen that all the samples having a $25 \%$ fiber ratio showed the highest strength. The maximum tensile strength $(55.95 \mathrm{MPa})$ was obtained from the composite having a fiber length of $12 \mathrm{~mm}$ and a fiber ratio of $25 \%$. In the same fiber ratio, composites having a fiber length of $12 \mathrm{~mm}$ exhibited a stable structure and gave the highest tensile strength. When the strain values were examined, it was seen that the strain value increased as the reinforcement ratio increased in the matrix. However, the strain values exhibited different behaviors for different fiber lengths and ratios. This could be explained by the agglomeration of fibers due to static electricity, leading to the inability to obtain a homogeneous mixture during production.

Fiber length and distribution are an important factor to be considered in tensile strength $[32,33]$. Takagi and Ichihara [34] indicated that the increase in fiber length improved their mechanical properties. It was determined that the tensile strength and elasticity module increased with increasing reinforcement length and started to decrease after a critical value $[35,36]$. They interpreted this because of low fiber-matrix adhesion [37]. 


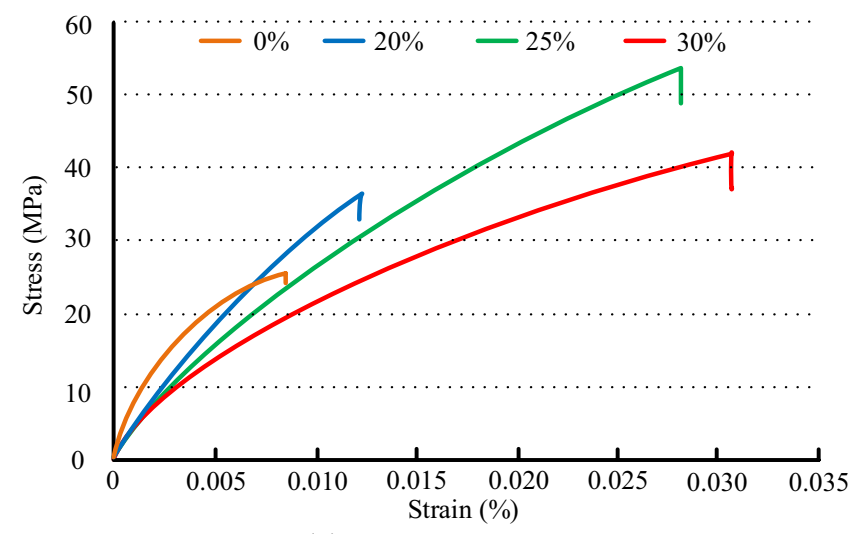

(a) Fiber length: $6 \mathrm{~mm}$

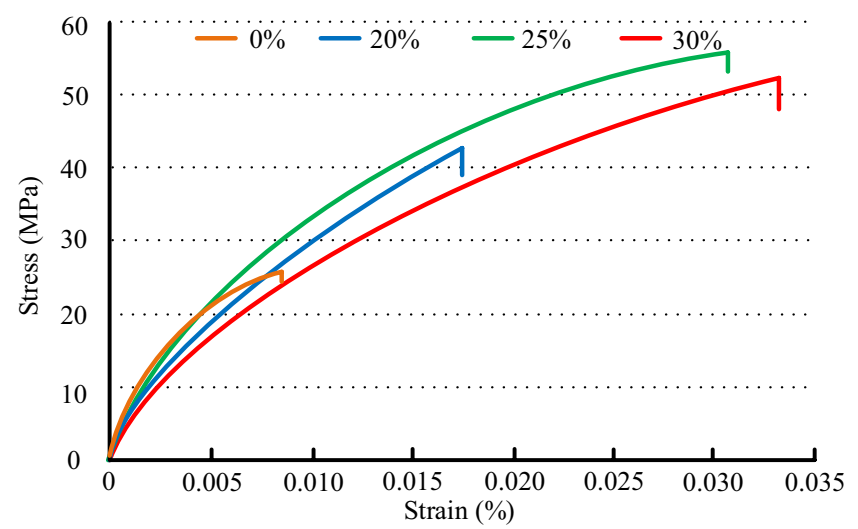

(c) Fiber length: $12 \mathrm{~mm}$

Fig. 6 Stress-strain diagrams of the composites

\subsection{Machinability results}

The cutting force has a significant impact on the machinability of the materials during the turning operation. Hence, it is crucial to understand the factors that affect machinability and to evaluate their effects. The effects of cutting forces on machinability have been investigated by various researchers, and investigations have been carried out to determine the appropriate cutting conditions.

Low cutting force means less cutting tool wear, less cost, and excellent surface quality. In this direction, the effects of turning parameters such as feed rate ( $f$ ), cutting speed (V), depth of cut, fiber length, and ratio on cutting force $(F)$ were investigated according to the Taguchi method. During turning tests of GFRP composites, $F_{x^{\prime}} F_{y,}$ and $F_{z}$ forces were measured with a dynamometer. The directions of the $F_{x^{\prime}} F_{y_{1}}$ and $F_{z}$ forces of the dynamometer connected to the CNC lathe are given in Fig. 7.

In Fig. 7, $F_{x^{\prime}} F_{y}$, and $F_{z}$ show the forces in directions of rotation, radial, and feed, respectively. The graph drawn by data obtained from the dynamometer is shown in Fig. 8.

Effects of fiber length, fiber rate, cutting speed, feed rate, and depth of cut on cutting force were determined

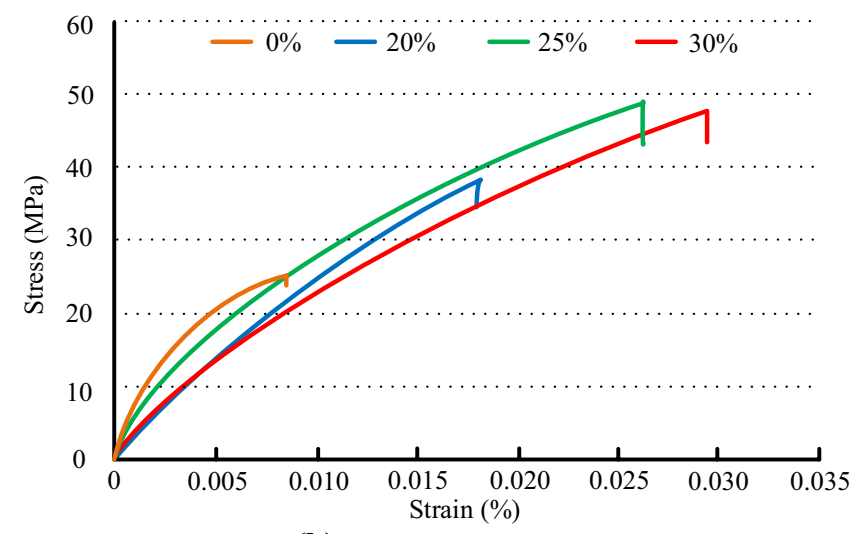

(b) Fiber length: 6-12 $\mathrm{mm}$

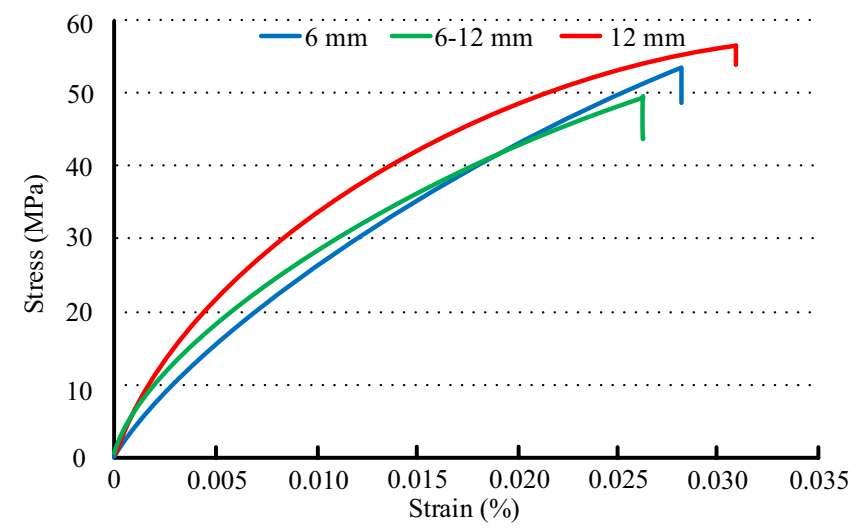

(d) Fiber ratio: $25 \%$

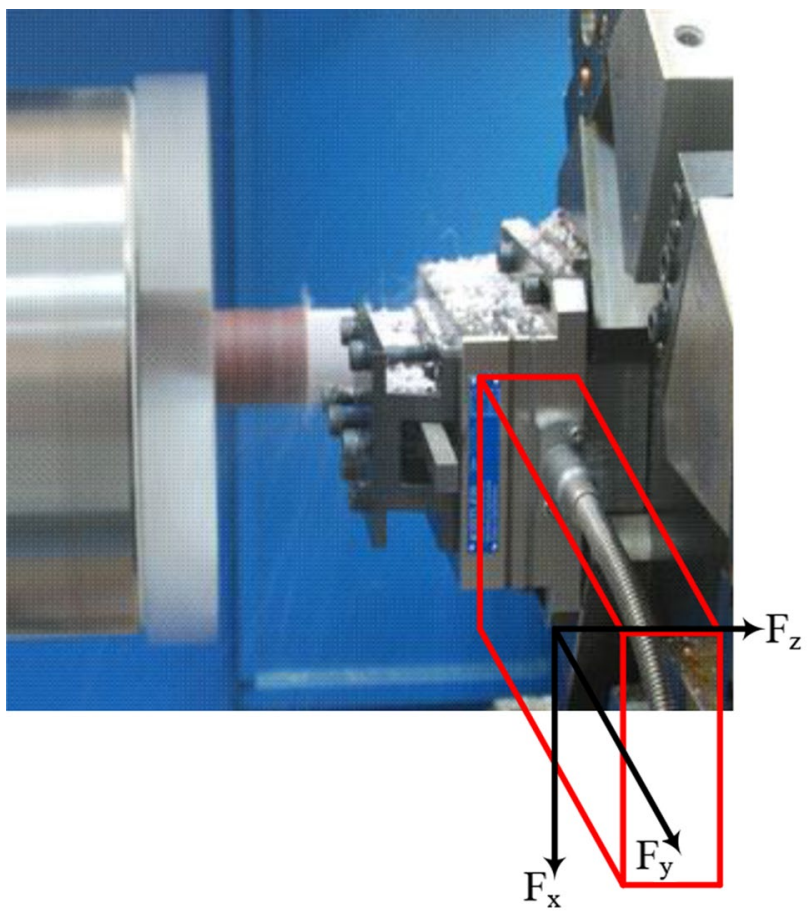

Fig. $7 F_{x^{\prime}} F_{y}$ and $F_{z}$ forces in dynamometer for turning experiments

\section{SN Applied Sciences}




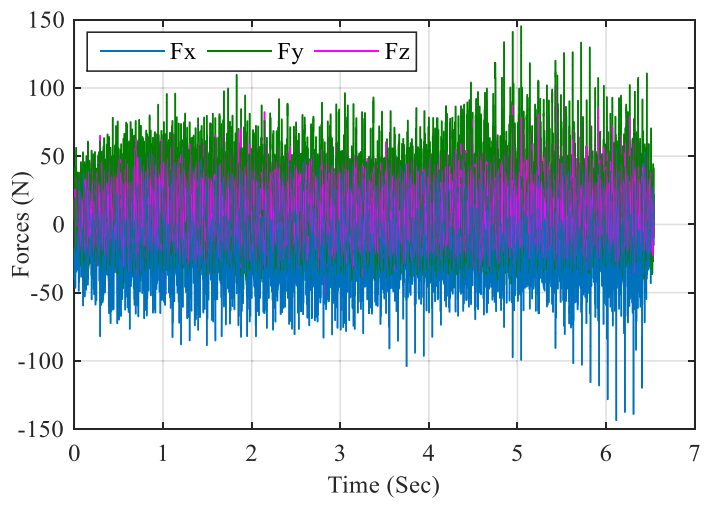

(a) Fiber length: $6-12 \mathrm{~mm}$, fiber ratio: 25\%, $\mathrm{V}: 120$ $\mathrm{m} / \mathrm{min}, \mathrm{f:} 0.1 \mathrm{~mm} / \mathrm{rev}, \mathrm{a}: 3 \mathrm{~mm}$

Fig. $8 F_{x^{\prime}} F_{y}$ and $F_{z}$ force diagrams in turning of GFRP composite

Main Effects Plot for SN ratios Data Means

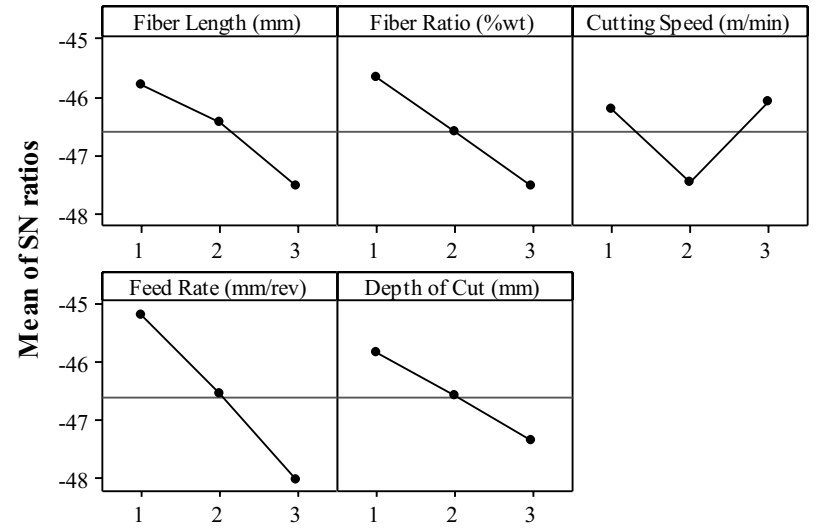

Signal-to-noise: Smaller is better

Fig. $9 \mathrm{~S} / \mathrm{N}$ ratios for cutting force

by entering all values in Taguchi $\mathrm{L}_{27}$ standard orthogonal array. The effects of the turning parameters on the cutting force were converted into graphs. The signal to noise ratio $(\mathrm{S} / \mathrm{N})$ obtained for the cutting forces depending on the turning parameters is given in Fig. 9, and the cutting force graphs are given in Fig. 10.

In Fig. 9, the smallest value was chosen as the best in $\mathrm{S} / \mathrm{N}$ to obtain minimum cutting force values. That means the absolute value of the ratios in the negative values on the $y$ axis in Fig. 9 was the smallest. It can be seen well in Fig. 10.

As shown in Fig. 10, cutting forces increased with increasing the fiber length and ratio. Since the increase in fiber length increased tensile strength, it could be thought that tensile strength had an essential effect on cutting force. On the other hand, the increase of the reinforcement rate caused to decrease the tensile strength after the

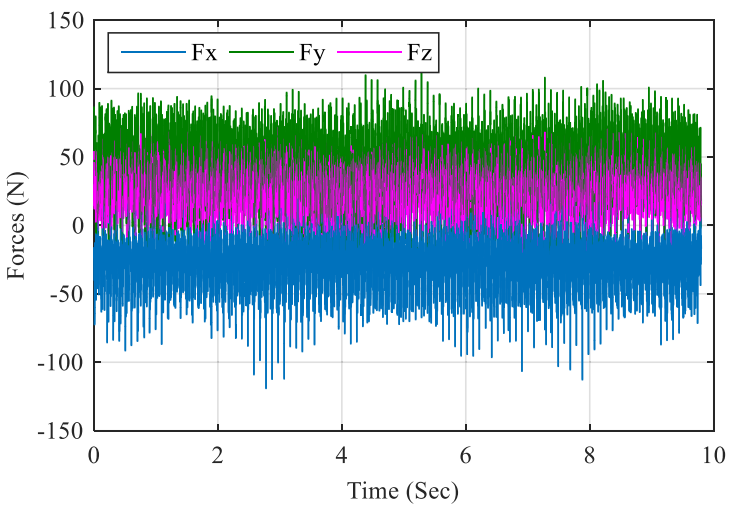

(b) Fiber length: $12 \mathrm{~mm}$, fiber ratio: $20 \%, \mathrm{~V}: 120 \mathrm{~m} / \mathrm{min}$, f: $0.2 \mathrm{~mm} / \mathrm{rev}, \mathrm{a}: 1 \mathrm{~mm}$

Main Effects Plot for Means Data Means

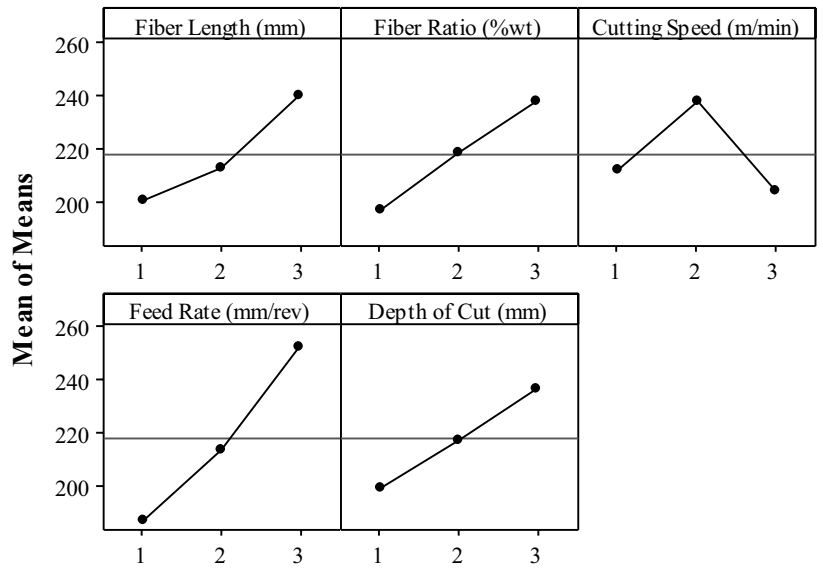

Fig. 10 Cutting force graph depending on turning parameters

reinforcement rate of $25 \%$, but there wasn't decrease in cutting force. This is because of the cutting force increases due to the fiber ratio during turning. Similarly, the increase in feed rate and depth of cut increased the cutting forces. However, the cutting force increased with increasing cutting speed from 40 to $80 \mathrm{~m} / \mathrm{min}$ and decreased with increasing cutting speed from 80 to $120 \mathrm{~m} / \mathrm{min}$. The minimum cutting force of $129.93 \mathrm{~N}$ was obtained from fiber length of $6 \mathrm{~mm}$, fiber ratio of $20 \%$, cutting speed of $40 \mathrm{~m} /$ $\mathrm{min}$, depth of cut of $1 \mathrm{~mm}$, and feed rate of $0.1 \mathrm{~mm} / \mathrm{rev}$. On the other hand, the maximum cutting force of $283.58 \mathrm{~N}$ was obtained from fiber length of $12 \mathrm{~mm}$, fiber rate of $25 \%$, cutting speed of $40 \mathrm{~m} / \mathrm{min}$, depth of cut of 3 , and feed rate of $0.3 \mathrm{~mm} / \mathrm{rev}$. Because the fiber material had excellent mechanical properties, the forces on the cutting tool increased during turning. Besides, the number of materials to be removed by the cutting tool increased with 
Table 5 Effect ranking on the cutting forces of the turning parameters

\begin{tabular}{llllll}
\hline Levels & Fiber length & Fiber ratio & Cutting speed & Feed rate & Depth of cut \\
\hline 1 & 200.5 & 197.1 & 212.3 & 187.8 & 199.9 \\
2 & 213.0 & 218.5 & 237.9 & 213.6 & 217.5 \\
3 & 240.4 & 238.3 & 203.8 & 252.7 & 236.6 \\
Delta & 40.0 & 41.2 & 34.0 & 64.9 & 36.7 \\
Effect rankings & 3 & 2 & 5 & 1 & 4 \\
\hline
\end{tabular}

increasing feed rate and depth of cut, and this situation increased the cutting forces on the cutting tool. A similar situation could be said for cutting speed up to a critical value. However, it started to behave different above this critical value. It is thought to be due to the heat generated by the friction between the cutting tool and the workpiece softening the matrix material. Similar results were reported by Paulo Davim et al. [38], Adam Khan and Senthil Kumar [39], and Kiliçkap et al. [40]. The effect of rankings of the turning parameters on the cutting force is given in Table 5 .

When the effect parameters produced by the Taguchi method were taken into consideration, the effect rankings on cutting force were feed rate, fiber rate, fiber length, depth of cut, and cutting speed. In turning GFRP composites, it was observed that the most effective parameter for cutting forces was feed rate, and the least one was cutting speed. Consequently, cutting speed, feed rate and depth of cut values should be selected optimal depending on tensile strength of composite materials. If not, plastic deformation wont occur and machinebility will be hard.

Surface quality is one of the most critical issues in machining. Deviations between axes, tolerances, and surface roughness are determined with surface quality for the parts to be machined. Generally, deviations depend on factors such as material, cutting tool, machine tool, and operator. Tolerances include the type of machine tool and compatibility of the workpiece and cutting tool. Surface roughness is affected by cutting tool type, tool geometry, cutting parameters, and environmental conditions. Considering the factors affecting the surface quality, surface roughness, which is closely related to the change of cutting parameters, is an essential factor. The effects of fiber length, fiber ratio, cutting speed, feed rate, and depth of cut on average surface roughness were determined by entering average surface roughness values in Taguchi $L_{27}$ standard orthogonal test design section, and the results were analyzed. The effects of the turning parameters on the average surface roughness were converted into graphs. The signal to noise ratio $(\mathrm{S} / \mathrm{N})$ for average surface roughness is given in Fig. 11, and the average surface roughness graph is given in Fig. 12.

In Fig. 11, the smallest value was chosen as the best in $\mathrm{S} / \mathrm{N}$ to obtain minimum average surface roughness values. In this context, the minimum values for $\mathrm{S} / \mathrm{N}$ were obtained
Main Effects Plot for SN ratios Data Means

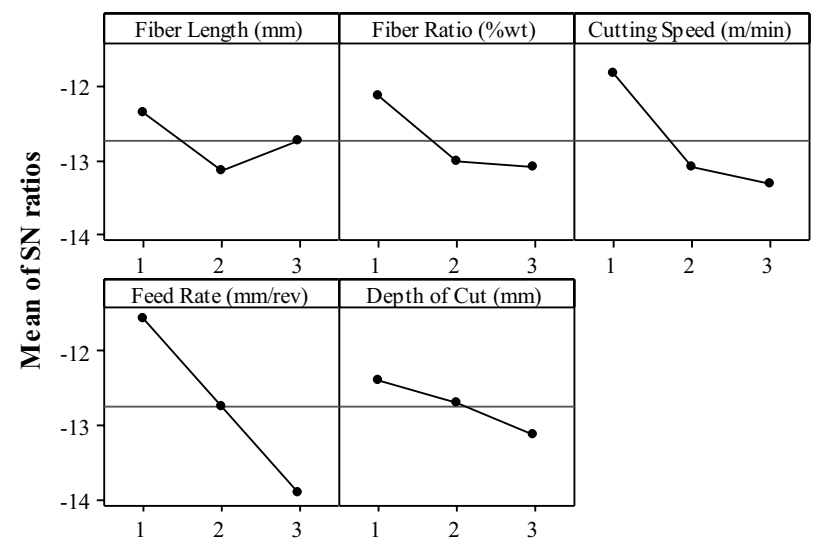

Signal-to-noise: Smaller is better

Fig. $11 \mathrm{~S} / \mathrm{N}$ ratios for surface roughness

Main Effects Plot for Means Data Means

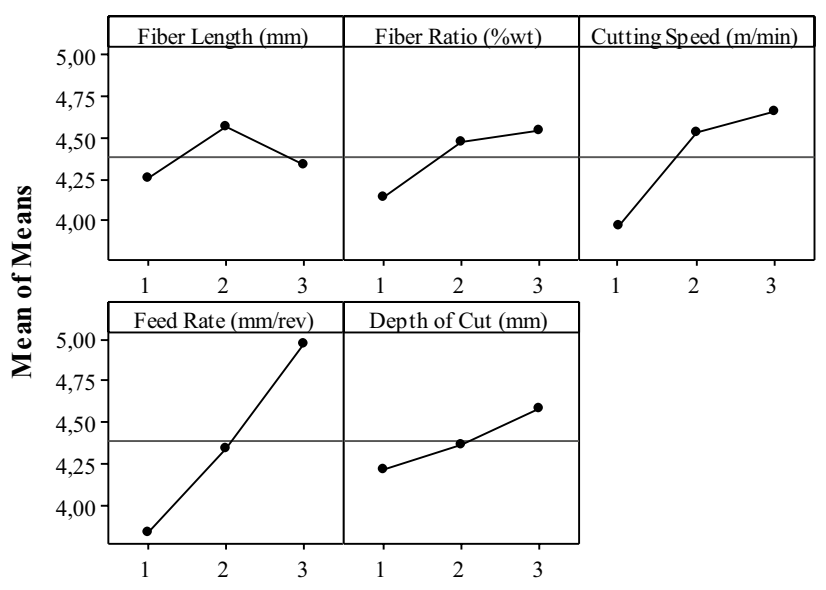

Fig. 12 Surface roughness graph depending on turning parameters

when levels of the fiber length, fiber ratio, cutting speed, feed rate, and depth of cut were 1 . The maximum values for $\mathrm{S} / \mathrm{N}$ were obtained when the level of fiber length was two and levels of the fiber ratio, feed rate, and depth of cut were 3. 
In Fig. 12, the average surface roughness value for the fiber length of $6 \mathrm{~mm}$ was quite low. The average surface roughness value for the fiber length of $6-12 \mathrm{~mm}$ was higher than the fiber length of $6 \mathrm{~mm}$ and $12 \mathrm{~mm}$. In this context, the worst surface quality was obtained from 6-12 $\mathrm{mm}$ fiber length. The reason might be that a fiber length of $6 \mathrm{~mm}$ and $12 \mathrm{~mm}$ reinforcement materials could not be homogeneously mixed. On the other hand, the surface roughness value on the machined surfaces increased with increasing fiber rate. It is thought that the fiber reinforcement elements don't get wet enough in the matrix. Giridharan et al. [37] also determined that poor bonding between matrix and reinforcement occurred with high fiber length and ratio. Therefore, high fiber content increased surface roughness.

When the effect of cutting speed, feed rate and depth of cut on the average surface roughness value was examined, it was seen that the average roughness value of the machined surfaces increased with increasing the values of these four factors.

The lowest average surface roughness value was measured as $2.95 \mu \mathrm{m}$ from fiber length of $6 \mathrm{~mm}$, fiber rate of $20 \%$, cutting speed of $40 \mathrm{~m} / \mathrm{min}$, depth of cut of $1 \mathrm{~mm}$, and feed rate of $0.1 \mathrm{~mm} / \mathrm{rev}$ parameters. The highest average surface roughness value was measured as $5.48 \mu \mathrm{m}$ from fiber length of $6 \mathrm{~mm}$, fiber rate of $30 \%$, cutting speed of $120 \mathrm{~m} / \mathrm{min}$, depth of cut of $3 \mathrm{~mm}$, and feed rate of $0.3 \mathrm{~mm} /$ rev parameters.

Taguchi's standard orthogonal array method successfully analyzed the effects of turning parameters on average surface roughness as being in the cutting force. The effect rankings of the turning parameters on the average surface roughness values are given in Table 6.

The effect rankings of the turning parameters on the average surface roughness values were feed rate, cutting speed, fiber ratio, depth of cut, and fiber length. In turning GFRP composites, it was observed that the most effective parameter for average surface roughness was feed rate; and the least one was fiber length.

In turning experiments carried out according to the Taguchi standard orthogonal array method, the results obtained from both experimental studies and the Taguchi method are given in Table 7. It was seen from Table 7 that the obtained actual and estimated values were close to each other. This situation showed that the Taguchi standard orthogonal array method provided excellent performance in turning experiments.

\section{Conclusion}

In this study, GF reinforcements having fiber lengths of $6 \mathrm{~mm}, 6-12 \mathrm{~mm}$, and $12 \mathrm{~mm}$ were mixed with polyester matrix materials at the weight ratio of $20 \%, 25 \%$, and $30 \%$ to obtain GFRP composite materials. The tensile strengths of composites were investigated. In addition, turning tests according to Taguchi standard orthogonal array method were performed in different cutting speed, feed rate, and depth of cut parameters. The effects of turning parameters on cutting force and surface roughness were analyzed. The results were as follows:

- Increasing fiber length and fiber ratio increased tensile strength. GFRP composites having a fiber length of $12 \mathrm{~mm}$ had higher tensile strength than the fiber length of $6 \mathrm{~mm}$ and $6-12 \mathrm{~mm}$. The highest tensile strengths were obtained from the fiber ratio of $25 \%$.

- The increase in fiber length, fiber ratio, feed rate, and depth of cut increased the forces on the cutting tool. On the other hand, the cutting force increased with increasing cutting speed from $40 \mathrm{~m} / \mathrm{min}$ to $80 \mathrm{~m} / \mathrm{min}$, and it decreased with increasing cutting speed from $80 \mathrm{~m} / \mathrm{min}$ to $120 \mathrm{~m} / \mathrm{min}$. The lowest cutting force was obtained from fiber length of $6 \mathrm{~mm}$, fiber ratio of $20 \%$, cutting speed of $40 \mathrm{~m} / \mathrm{min}$, depth of cut of $1 \mathrm{~mm}$, and feed rate of $0.1 \mathrm{~mm} / \mathrm{rev}$ parameters. The highest cutting forces were obtained from the fiber length of $12 \mathrm{~mm}$, fiber ratio of $25 \%$, cutting speed of $40 \mathrm{~m} / \mathrm{min}$, depth of cut of $3 \mathrm{~mm}$, and feed rate of $0.3 \mathrm{~mm} / \mathrm{rev}$ parameters. The most effective parameter on cutting force was feed rate and then fiber ratio. The least effective parameter was cutting speed.

- The average surface roughness values increased with increasing the fiber ratio, cutting speed, feed rate, and depth of cut. While the best average surface roughness value was obtained from the fiber length of $6 \mathrm{~mm}$, fiber ratio of $20 \%$, cutting speed of $40 \mathrm{~m} / \mathrm{min}$, depth of cut of $1 \mathrm{~mm}$, and feed rate of $0.1 \mathrm{~mm} / \mathrm{rev}$,
Table 6 Effect ranking on the average surface roughness of the turning parameters

\begin{tabular}{llllll}
\hline Levels & Fiber length & Fiber ratio & Cutting speed & Feed rate & Depth of cut \\
\hline 1 & 4.257 & 4.137 & 3.971 & 3.838 & 4.214 \\
2 & 4.566 & 4.479 & 4.534 & 4.346 & 4.366 \\
3 & 4.340 & 4.547 & 4.657 & 4.979 & 4.582 \\
Delta & 0.309 & 0.410 & 0.686 & 1.141 & 0.368 \\
Effect rankings & 5 & 3 & 2 & 1 & 4 \\
\hline
\end{tabular}


Table 7 Experimental (actual) and estimated values

\begin{tabular}{|c|c|c|c|c|c|c|c|c|c|}
\hline \multirow[t]{2}{*}{ Exp. } & \multirow[t]{2}{*}{ Fiber length } & \multirow[t]{2}{*}{ Fiber ratio } & \multirow[t]{2}{*}{$\begin{array}{l}\text { Cutting } \\
\text { speed }\end{array}$} & \multirow[t]{2}{*}{ Feed rate } & \multirow[t]{2}{*}{ Depth of cut } & \multicolumn{2}{|c|}{ Cutting force $(\mathrm{N})$} & \multicolumn{2}{|c|}{$\begin{array}{l}\text { Surface roughness } \\
(\mu \mathrm{m})\end{array}$} \\
\hline & & & & & & Actual & Estimated & Actual & Estimated \\
\hline 1 & 1 & 1 & 1 & 1 & 1 & 129.93 & 125.564 & 2.95 & 2.86704 \\
\hline 2 & 1 & 1 & 1 & 1 & 2 & 135.48 & 143.226 & 3.06 & 3.01815 \\
\hline 3 & 1 & 1 & 1 & 1 & 3 & 165.63 & 162.250 & 3.11 & 3.23481 \\
\hline 4 & 1 & 2 & 2 & 2 & 1 & 186.20 & 198.324 & 4.31 & 4.28037 \\
\hline 5 & 1 & 2 & 2 & 2 & 2 & 219.13 & 215.986 & 4.33 & 4.43148 \\
\hline 6 & 1 & 2 & 2 & 2 & 3 & 243.99 & 235.010 & 4.72 & 4.64815 \\
\hline 7 & 1 & 3 & 3 & 3 & 1 & 225.94 & 223.211 & 5.06 & 5.10370 \\
\hline 8 & 1 & 3 & 3 & 3 & 2 & 246.29 & 240.873 & 5.29 & 5.25481 \\
\hline 9 & 1 & 3 & 3 & 3 & 3 & 251.75 & 259.896 & 5.48 & 5.47148 \\
\hline 10 & 2 & 1 & 2 & 3 & 1 & 223.15 & 228.587 & 4.92 & 4.88037 \\
\hline 11 & 2 & 1 & 2 & 3 & 2 & 247.85 & 246.250 & 5.01 & 5.03148 \\
\hline 12 & 2 & 1 & 2 & 3 & 3 & 269.11 & 265.273 & 5.23 & 5.24815 \\
\hline 13 & 2 & 2 & 3 & 1 & 1 & 154.13 & 151.047 & 3.98 & 4.20370 \\
\hline 14 & 2 & 2 & 3 & 1 & 2 & 164.58 & 168.710 & 4.25 & 4.35481 \\
\hline 15 & 2 & 2 & 3 & 1 & 3 & 188.78 & 187.733 & 4.90 & 4.57148 \\
\hline 16 & 2 & 3 & 1 & 2 & 1 & 208.24 & 205.161 & 4.11 & 4.09370 \\
\hline 17 & 2 & 3 & 1 & 2 & 2 & 222.27 & 222.823 & 4.23 & 4.24481 \\
\hline 18 & 2 & 3 & 1 & 2 & 3 & 239.32 & 241.846 & 4.46 & 4.46148 \\
\hline 19 & 3 & 1 & 3 & 2 & 1 & 187.98 & 182.877 & 4.15 & 4.14370 \\
\hline 20 & 3 & 1 & 3 & 2 & 2 & 204.13 & 200.540 & 4.38 & 4.29481 \\
\hline 21 & 3 & 1 & 3 & 2 & 3 & 210.87 & 219.563 & 4.42 & 4.51148 \\
\hline 22 & 3 & 2 & 1 & 3 & 1 & 252.35 & 251.814 & 4.53 & 4.43370 \\
\hline 23 & 3 & 2 & 1 & 3 & 2 & 273.86 & 269.476 & 4.59 & 4.58481 \\
\hline 24 & 3 & 2 & 1 & 3 & 3 & 283.58 & 288.500 & 4.70 & 4.80148 \\
\hline 25 & 3 & 3 & 2 & 1 & 1 & 230.97 & 232.304 & 3.92 & 3.92370 \\
\hline 26 & 3 & 3 & 2 & 1 & 2 & 244.26 & 249.966 & 4.15 & 4.07481 \\
\hline 27 & 3 & 3 & 2 & 1 & 3 & 276.03 & 268.990 & 4.22 & 4.29148 \\
\hline
\end{tabular}

the worst value was obtained from the fiber length of $6 \mathrm{~mm}$, fiber ratio of $30 \%$, cutting speed of $120 \mathrm{~m} /$ $\mathrm{min}$, depth of cut of $3 \mathrm{~mm}$, and feed rate of $0.3 \mathrm{~mm} /$ rev. It was found that the most effective parameter for average surface roughness was feed rate, and the least effective parameter was fiber length.

\begin{abstract}
Acknowledgments This study was financially supported by Batman University Scientific Research Projects Unit (BTÜBAP) within the scope of project 2018-Master's Degree-5. We would like to thank Batman University for their financial support. We also would like to thank BUMER (Batman University, Central Research Laboratory) for allowing us to use their laboratory facilities during this research.
\end{abstract}

\section{Compliance with ethical standards}

Conflict of interest The authors declare that they have no competing interests.

\section{References}

1. Ramesh B, Eswari S, Sundararajan T (2020) Flexural behaviour of glass fibre reinforced polymer (GFRP) laminated hybridfibre reinforced concrete beams. SN Appl Sci 2:204. https://doi. org/10.1007/s42452-020-1966-2

2. Çelik YH, Kilickap E, Koçyiğ it N (2019) Evaluation of drilling performances of nanocomposites reinforced with graphene and graphene oxide. Int J Adv Manuf Technol 100(9-12):2371-2385. https://doi.org/10.1007/s00170-018-2875-z

3. Kumar P, Vengal K, Kundavarapu R, Ravishankar V, Venkata D, Kaki R (2020) Modeling of glass fiber reinforced composites for optimal mechanical properties using teaching learning-based optimization and artificial neural networks. SN Appl Sci 2(1):131. https://doi.org/10.1007/s42452-019-1837-x

4. Sivasankaran S, Harisagar PT, Saminathan E, Siddharth S, Sasikumar P (2014) Effect of process parameters in surface roughness during turning of GFRP pipes using PCD insert tool. Procedia Eng 97:64-71. https://doi.org/10.1016/j.proeng.2014.12.225

5. Jawali ND, Siddeswarappa B, Siddaramaiah (2006) Physicomechanical properties, machinability, and morphological behavior 
of short glass fiber-reinforced nylon 6 composites. J Reinf Plast Compos 25:1409-1418. https://doi.org/10.1177/0731684406 066675

6. Autay R, Missaoui S, Mars J, Dammak F (2019) Mechanical and tribological study of short glass fiber-reinforced PA 66. Polym Polym Compos 27(9):587-596. https://doi.org/10.1177/09673 91119853956

7. Vijay BR, Srikantappa AS (2019) Physico-mechanical and tribological properties of glass fiber based epoxy composites. Int J Mech Eng Rob Res 8(6):929-934. https://doi.org/10.18178/ijmer r.8.6.929-934

8. Çelik Y, Kılıçkap E, Yardımeden A (2013) Estimate of cutting forces and surface roughness in end milling of glass fiber reinforced plastic composites using fuzzy logic system. Sci Eng Compos Mater 21(3):435-443. https://doi.org/10.1515/secm-2013-0129

9. Pazhanivel K, Bhaskar GB, Elayaperumal A, Anandan P, Arunachalam S (2019) Influence of Ni-Ti shape memory alloy short fibers on the flexural response of glass fiber reinforced polymeric composites. SN Appl Sci 1:789. https://doi.org/10.1007/s4245 2-019-0823-7

10. Chang CS, Lin YL, Hwang BC (2008) Prediction of cutting temperatures in turning of glass fiber reinforced plastics (GFRP) materials. J Mech 24:357-368. https://doi.org/10.1017/S1727 719100002483

11. Chang CS (2006) Turning of glass-fiber reinforced plastics materials with chamfered main cutting-edge carbide tools. J Mater Process Technol 180(1-3):117-129. https://doi.org/10.1016/j. jmatprotec.2006.05.011

12. Naveen Sait A, Aravindan S, Noorul Haq A (2009) Optimisation of machining parameters of glass-fibre-reinforced plastic (GFRP) pipes by desirability function analysis using Taguchi technique. Int J Adv Manuf Technol 43:581-589. https://doi.org/10.1007/ s00170-008-1731-y

13. Chegdadi F, El Mansori M (2019) Tribo-functional effects of double-crossed helix on surface finish, cutting friction and tool wear mechanisms during the milling process of natural fiber composites. Wear 426-427:1507-1514. https://doi.org/10.1016/j. wear.2018.11.026

14. Kuo CL, Soo SL, Aspinwall DK, Carr C, Bradley S, M'Saoubi R, Leahy W (2019) Development of single step drilling technology for multilayer metallic-composite stacks using uncoated and PVD coated carbide tools. J Manuf Process 31:286-300. https:// doi.org/10.1016/j.jmapro.2017.11.026

15. Ozkan D, Panjan P, Gok MS, Karaoglanli AC (2019) Investigation of machining parameters that affects surface roughness and cutting forces in milling of CFRPs with TiAIN and TiN coated carbide cutting tools. Mater Res Express 6(9):095616. https://doi. org/10.1088/2053-1591/ab30de

16. Sarma PMMS, Karunamoorthy L, Palanikumar K (2008) Modeling and analysis of cutting force in turning of GFRP composites by CBN tools. J Reinf Plast Compos 27:711-723. https://doi. org/10.1177/0731684407084214

17. Işık B, Kentli A (2009) Multicriteria optimization of cutting parameters in turning of UD-GFRP materials considering sensitivity. Int J Adv Manuf Technol 44:1144-1153. https://doi. org/10.1007/s00170-009-1927-9

18. Gill SK, Gupta M, Satsangi PS (2013) Prediction of cutting forces in machining of unidirectional glass fiber reinforced plastics composite. Front Mech Eng 8:187-200. https://doi.org/10.1007/ s11465-013-0262-x

19. Paulo Davim J, Mata F (2007) New machinability study of glass fibre reinforced plastics using polycrystalline diamond and cemented carbide (K15) tools. Mater Des 28(3):1050-1054. https ://doi.org/10.1016/j.matdes.2005.09.019

20. Davim JP, Mata F (2005) A new machinability index in turning fiber reinforced plastics. J Mater Process Technol
170(1-2):436-440. https://doi.org/10.1016/j.jmatprotec .2005 .05 .047

21. Hussain S, Pandurangadu V, Kumar K (2011) Cutting power prediction model for turning of GFRP composites using response surface methodology. Int J Eng Sci Technol 3(6):161171. https://doi.org/10.4314/ijest.v3i6.13

22. Işık $B$ (2008) Experimental investigations of surface roughness in orthogonal turning of unidirectional glass-fiber reinforced plastic composites. Int J Adv Manuf Technol 37:42-48. https ://doi.org/10.1007/s00170-007-0946-7

23. Yardimeden A (2016) Investigation of optimum cutting parameters and tool radius in turning glass-fiber-reinforced composite material. Sci Eng Compos Mater 23(1):85-92. https://doi. org/10.1515/secm-2013-0301

24. Giasin K, Gorey G, Byrne C, Sinke J, Brousseau E (2019) Effect of machining parameters and cutting tool coating on hole quality in dry drilling of fibre metal laminates. Compos Struct 212:159-174. https://doi.org/10.1016/j.compstruct .2019.01.023

25. Xu J, Ji M, Paula Davim J, Chen M, El Mansori M, Krishnaraj V (2020) Comparative study of minimum quantity lubrication and dry drilling of CFRP/titanium stacks using TiAIN and diamond coated drills. Compos Struct 234:111727. https://doi. org/10.1016/j.compstruct.2019.111727

26. Palanikumar K (2006) Cutting parameters optimization for surface roughness in machining of GFRP composites using Taguchi's method. J Reinf Plast Compos 25:1739-1751. https://doi. org/10.1177/0731684406068445

27. Kumar Parida A, Das R, Sahoo AK, Routara BC (2014) Optimization of cutting parameters for surface roughness in machining of GFRP composites with graphite/fly ash filler. Procedia Mater Sci 6:1533-1538. https://doi.org/10.1016/j.mspro.2014.07.134

28. Hussain SA, Pandurangadu V, Kumar KP (2014) Optimization of surface roughness in turning of GFRP composites using genetic algorithm. Int J Eng Sci Technol 6:49-57. https://doi. org/10.4314/ijest.v6i1.6

29. Gupta M, Kumar S (2015) Investigation of surface roughness and MRR for turning of UD-GFRP using PCA and Taguchi method. Eng Sci Technol an Int J 18:70-81. https://doi.org/10.1016/j.jestc h.2014.09.006

30. Vasudevan H, Deshpande NC, Rajguru RR (2014) Grey fuzzy multiobjective optimization of process parameters for CNC turning of GFRP/Epoxy composites. Procedia Eng 97:85-94. https://doi. org/10.1016/j.proeng.2014.12.228

31. Sharma S, Tamang S, Devarasiddappa D, Chandrasekran M (2014) Fuzzy logic modeling and multiple performance optimization in turning GFRP composites using desirability function analysis. Procedia Mater Sci 6:1805-1814. https://doi. org/10.1016/j.mspro.2014.07.211

32. Fu S-Y, Lauke B (1996) Effect of fiber length and fiber orientation distributions on the tensile strength of short-fiber-reinforced polymers. Compos Sci Technol 56:1179-1190

33. Elkazaz E, Crosby WA, Ollick AM, Elhadary M (2020) Effect of fiber volume fraction on the mechanical properties of randomly oriented glass fiber reinforced polyurethane elastomer with crosshead speeds. Alex Eng J 59(1):209-216. https://doi. org/10.1016/j.aej.2019.12.024

34. Takagi $\mathrm{H}$, Ichihara $\mathrm{Y}$ (2004) Effect of fiber length on mechanical properties of "green" composites using a starch-based resin and short bamboo fibers. JSME Int J Ser A 47(4):551-555. https://doi. org/10.1299/jsmea.47.551

35. Venkateshwaran N, Elaya Perumal A, Jagatheeshwaran MS (2011) Effect of fiber length and fiber content on mechanical properties of banana fiber/ epoxy composite. J Reinf Plast Compos 30(19):1621-1627. https://doi.org/10.1177/0731684411 426810 
36. Capela C, Oliveira SE, Pestane J, Ferreira JAM (2017) Effect of fiber length on the mechanical properties of high dosage carbon reinforced. Procedia Struct Integr 5:539-546. https://doi. org/10.1016/j.prostr.2017.07.159

37. Giridharan R, Raatan VS, Jenarthanan MP (2019) Experimental study on effect of fiber length and fiber content on tensile and flexural properties of bamboo fiber/epoxy composite. Multidiscip Model Mater Struct 15(5):947-957. https://doi.org/10.1108/ MMMS-11-2018-0194

38. Paulo Davim J, Silva LR, Festas A, Abrão AM (2009) Machinability study on precision turning of PA66 polyamide with and without glass fiber reinforcing. Mater Des 30:228-234. https://doi. org/10.1016/j.matdes.2008.05.003
39. Adam Khan M, Senthil Kumar A (2011) Machinability of glass fibre reinforced plastic (GFRP) composite using alumina-based ceramic cutting tools. J Manuf Process 13:67-73. https://doi. org/10.1016/j.jmapro.2010.10.002

40. Kiliçkap E, Yardimeden A, Çelik YH (2015) Investigation of experimental study of end milling of CFRP composite. Sci Eng Compos Mater 22:89-95. https://doi.org/10.1515/secm-2013-0143

Publisher's Note Springer Nature remains neutral with regard to jurisdictional claims in published maps and institutional affiliations. 